\title{
A Note on \\ Transliteration
}

All italicized technical terms from Hindi and Sanskrit and the titles of literary works have been transliterated according to the system followed by the Library of Congress, with the exception that for Hindi words the medial and final vowel $a$, which is usually not pronounced, has been omitted from most words (thus Rämcaritmānas rather than Rāmacaritamanasa). However, for certain words that end with conjunct consonants, the final vowel has been retained (bhakta), as native speakers often add a slight vowel in such cases and this form may likewise be more readily pronounced by readers. The final vowel has also been retained in a few words that have become familiar to English readers in Sanskrit-derived transliterations (karma, dharma, yoga). In transliterations of medieval Hindi verses, however, all vowels are shown, since they are normally pronounced for metrical reasons. The nasalization of a final vowel (anunāsika) is indicated by $m$ (mem, gosāīn $)$.

For readability and to avoid an excess of diacritics, a different approach has been adopted for proper nouns. These are given without diacritics and with the substitution of $s h$ for both the consonants $श$ and ष, of $c h$ for both च and छ, of ksh for क्ष, and of $r i$ for ॠ (thus Ramchandra, Lakshman, Krishna). Certain common Anglicizations have been adopted, generally following Webster's Ninth Collegiate (swami, ashram, sadhu, Singh), and place names have generally been given in common English spellings (Vrindavan, Kashi, Rewa). The names of modern Indian authors who write in English are presented as 
they themselves transliterate them. As noted above for technical terms, so in the case of names, final conjuncts have generally been joined to a short vowel (Mishra, Shukla); so too the names of certain deities that may be familiar to readers in such spellings (Shiva, Garuda). The names of castes and dialects follow the same rules (Brahman, Kshatriya, Khari Boli). For those who wish to be certain of pronounciation, an appended glossary provides proper nouns with diacritics.

Throughout this book, the term "Ramayan" is used to designate the broad tradition of retellings of the Ram narrative, and in occasional references by Hindi speakers to their Ramayan, that is, the Rämcaritmānas; the Sanskritic transliteration (Rämäyana) refers only to Sanskrit works so titled. 